\title{
Evaluación del Potencial Solar de Techumbres Mediante Drones + BIM
}

\author{
BIM + UAV Assessment of Roofs' Solar Potential
}

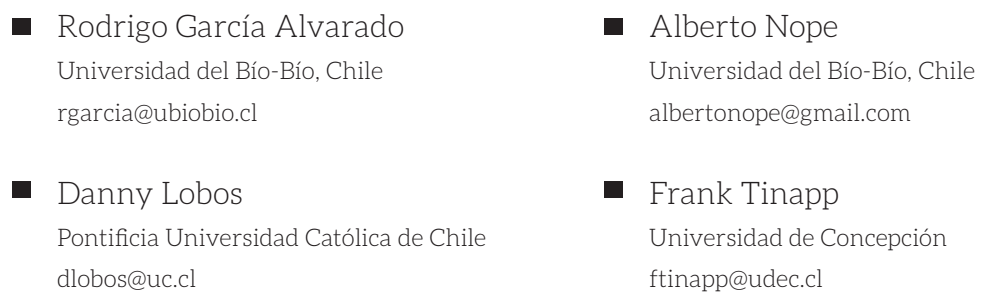

\begin{abstract}
This paper describes a novel method for determining the capacity to generate solar energy integrated into the roofs of buildings by aerial survey using UAVs and BIM models for sizing the covering surfaces and integration of solar panels. Various digital procedures are enchained like planning of trajectories, image processing, geometric reconstitution, simulation of solar radiation and calculation of energy generation to promote on-site installation of clean energy sources in existing buildings, to ensure a more sustainable habitat.
\end{abstract}

Keywords: BIM, UAV, Solar Energy, Sustainable Building

\section{Introducción}

La energía solar posee un gran potencial para suplir las crecientes demandas ambientales de los edificios (Lund, 2012). En particular mediante la integración de paneles captadores, especialmente en las techumbres, sin embargo debe evaluarse las condiciones apropiadas en cada edificio. En edificios existentes, usualmente no se dispone de planos de ejecución y/o presentan diversas intervenciones en sus techumbres. Por esta razón, este articulo propone un procedimiento de evaluación aérea del potencial solar en cubiertas, mediante la programación de recorridos de vehículos aéreos no-tripulados (drones), la recolección de fotografías clave, la restitución geométrica y material, y el análisis de radiación solar recibida, para estimar la capacidad de instalación de equipos de captación y sus posibilidades de generación energética para las demandas locales. Este procedimiento integra trabajo en terreno, estudios geométricos y simulación energética, basado en condiciones generales de edificios e información técnica de paneles solares.

Existen diversas posibilidades de levantamiento aéreo de zonas urbanas (como LIDAR: Light Detection and Ranging), que reconstituyen la volumetría general de los edificios mediante vuelos de altitud y lectura óptica general, y en base a estos registros algunas implementaciones computacionales (como Mapwell) permiten evaluar la capacidad solar de las techumbres (Alexander et al, 2009), pero son de alto costo y no otorgan un detalle suficiente sobre las condiciones geométricas otécnicas delas cubiertas. Los vuelos independientes mediante vehículos aéreos no tripulados (UAV: Unmanned aerial vehicles, también conocidos como drones) se han popularizado al contar con equipos de bajo costo, pero usualmente las trayectorias no son preparadas y difícilmentecontroladas de manera interactiva por las condiciones climáticas $u$ obstrucciones en el entorno. Demanera similar las tomas fotográficas normalmente son continuas, interrumpidas por obstáculos, con excesiva apertura visual y no completan adecuadamente los costados para una restitución geométrica de volúmenes tridimensionales. Las techumbres poseen una configuración prismática sencilla, pero usualmente interrumpida por ductos, volúmenes menores o salientes que impiden su reconocimiento completo y deben interpretarse combinando vistas. El análisis de radiación solar puede realizarse en volúmenes geométricos mediante software de cálculo ambiental, pero debe estar calibrado y con la información adecuada para generar resultados fiables. Por lo que el procedimiento sugerido pretende encadenar la capacidad de registro de los drones, con análisis integrados en modelos de edificios (BIM: building information modeling), para desarrollar un estimación fiable y efectiva de la generación energética solar, esto debido a las capacidades de esta tecnología de modelar objetos constructivos (techos, 
muros, losas, etc) y almacenar diversas propiedades (medidas, vínculos, costos, etc) (Eastman et al., 2011), incluso aspectos térmicos (Bazjanac, 2008 y Lobos et al 2014).

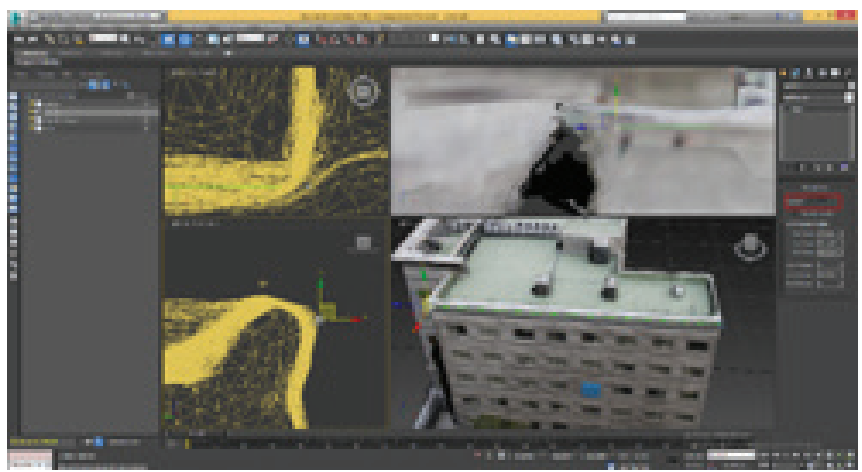

Figura 1: Pruebas de restitución geométrica de techumbres mediante secuencias de imágenes aéreas (N.Lazcani).

\section{Desarrollo}

Para establecer el procedimiento se han efectuado primero experimentos parciales con distintos software y tomas en terreno, verificando las configuraciones y pasos a realizar (Fig.1). Por un lado, preparando la programación de trayectorias en modeladores tridimensionales, basado en proporciones generales de los edificios que permitan sugerir al controlador de vuelo unas posiciones relativas para las tomas fotográficas, las cuales deben adaptarse en terreno según los obstáculos circundantes. Esto se ha preparado con desplazamientos de cámaras, que permiten utilizar render de prueba para la restitución geométrica en algunos casos de estudios típicos de edificios en altura y viviendas unifamiliares Por otro lado, se han realizado vuelos libres en algunos edificios existentes, recopilando las tomas y extrayendo fotogramas para efectuar restituciones mediante software de análisis geométrico a partir de imágenes y calibración de lentes. Las pruebas han permitido determinar las condiciones de encuadre y puntos de vista primordiales para limitar la cantidad de vistas y alcanzar una restitución completa de la cubierta. Además se ha probado la transferencia del archivo geométrico a software de modelación para refinar el trazado de trayectorias sugeridas, y por otro a software de análisis de radiación solar. En estos cálculos se han comparado resultados de diferentes casos, según recolección por paramento y bases climáticas adoptadas para verificar que las estimaciones sean consistentes con mediciones reales efectuadas, determinando un modelo climático fiable.

Así mismo se han revisado condiciones de instalación de distintos paneles solares y sus requerimientos constructivos en cuanto a soporte y disposición geométrica, considerando en particular losintegradosen cubiertasinclinadaso sobrepuestos en cubiertas planas. Efectuando una tabla de requerimientos

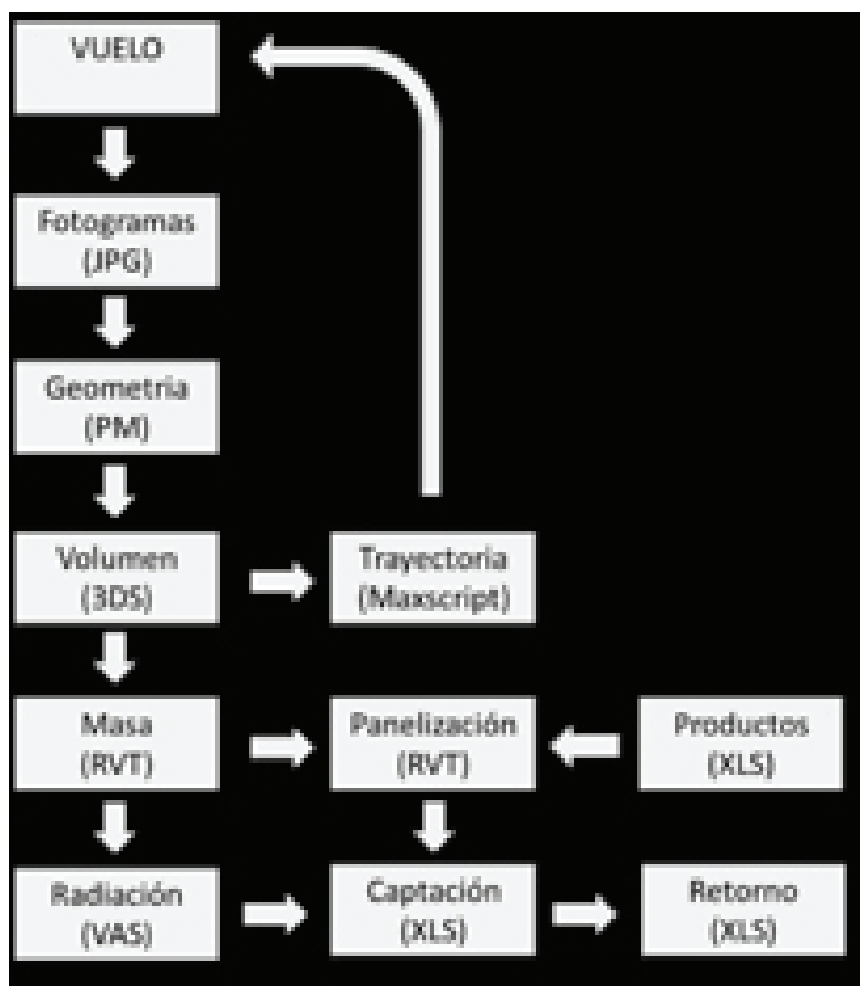

Figura 2: Esquema general de la metodología.

y márgenes de magnitud aplicables según cantidad de paneles. Implementando en una planilla de cálculo, según superficie y radiación de cada faldón de techumbre útil, para determinar la cantidad de paneles y de acuerdo a su eficiencia, estimar la capacidad de recolección energética, asumiendo finalmente el total estimado en distintas tecnologías (térmica, fotovoltaica o hibrida). Considerando perdidas de superficies irregulares y franjas de circulación para reparaciones, así como márgenes de instalación. Se han seleccionado características de los paneles usualmente disponibles y se han estimado distribuciones entre equipos según el perfil de demandas energéticas usuales del edificio, además de posibilidad de alimentar a la red urbana en periodos de excedente eléctrico.

De este modo se integra un flujo digital de datos (Fig.2), desde el vuelo aéreo hasta el análisis de instalación de paneles solares, mediante un modelo del edificio, con la restitución geométrica a partir de imágenes y cálculo de radiación solar de la cubierta. Proveyendo a su vez la programación de la trayectoria de vuelo

\section{Caso de Estudio}

Para exponer el proceso se presenta la elaboración del registro, restitución y análisis de una vivienda uni-familiar situada en Concepción, Chile (LAT. 36 46' 22" S y LONG. $73^{\circ}$ 03 ' 47" O). 


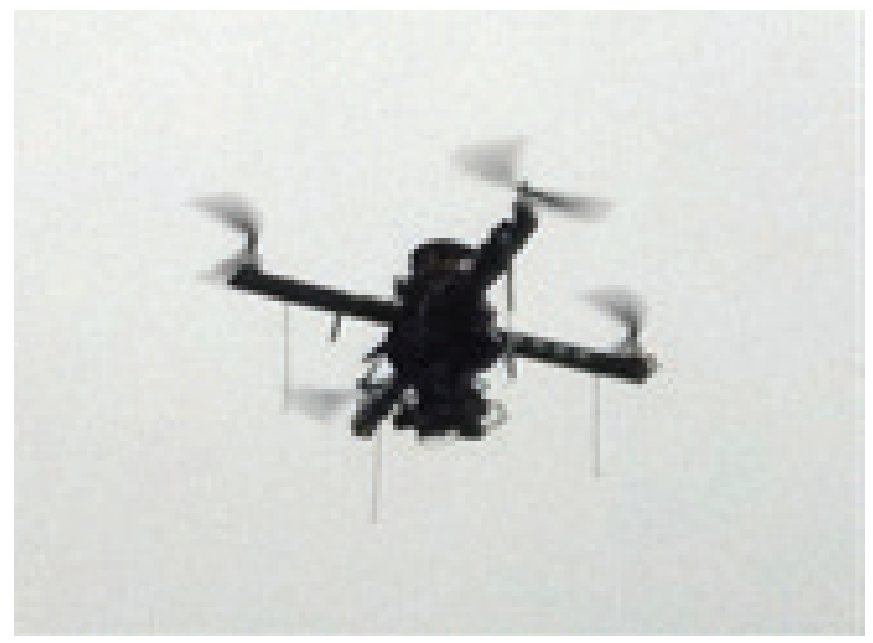

Figura 3: Multicóptero utilizado en las pruebas.

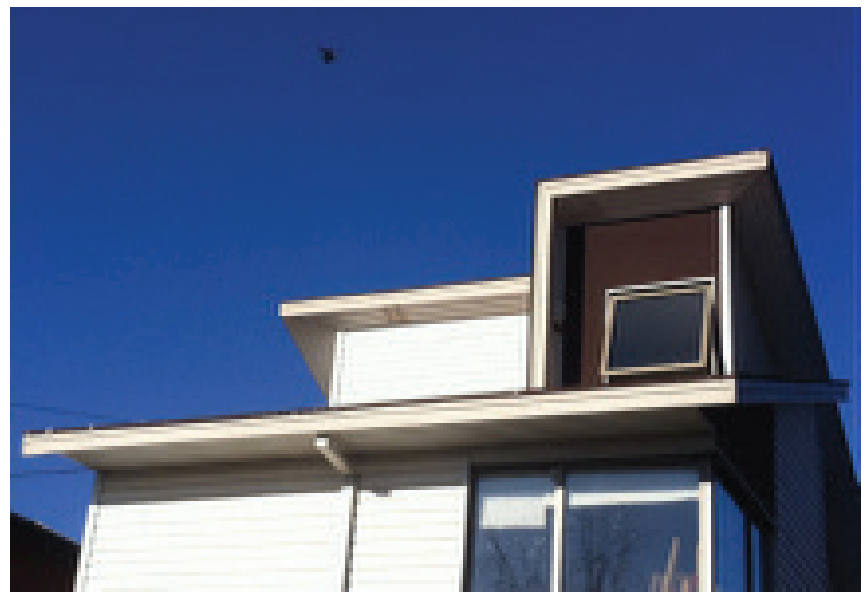

Figura 3: Vuelo del Dron sobre la vivienda de prueba.

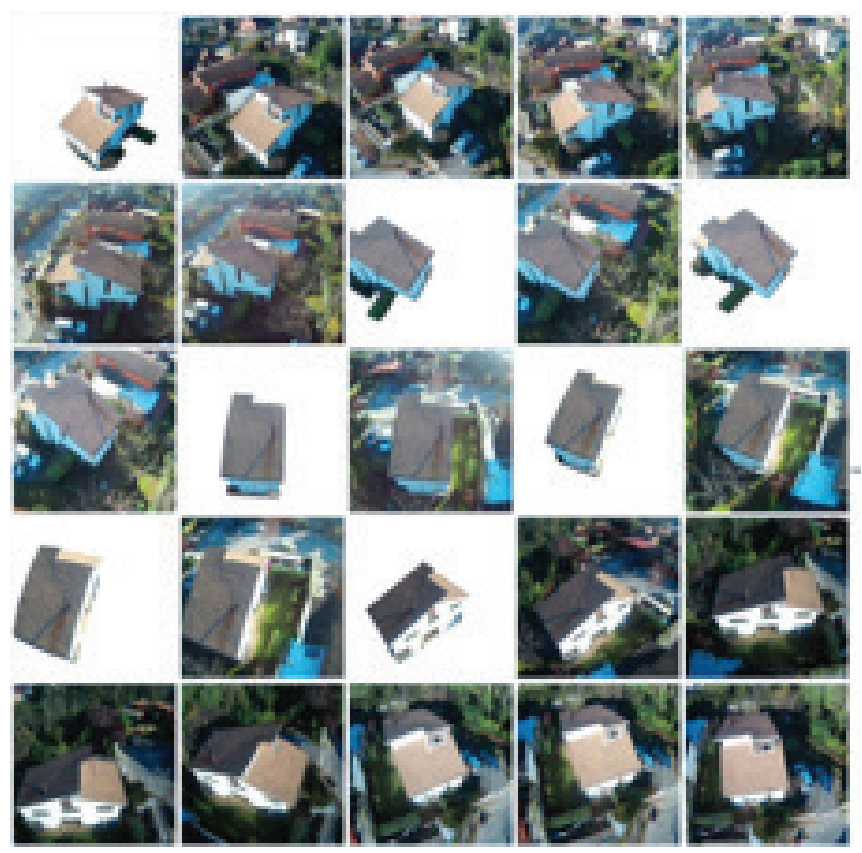

Figura 4: Imágenes de Vuelo.
El UAV utilizado en este estudio es un multicóptero de cuatro motores, capaz de levantar una masa de carga útil de máximo 500 gr. La autonomía de vuelo de este sistema es limitada a 10 minutos con $25 \%$ de reserva y la misión se controla utilizando un sistema comercial de autopiloto modelo Pixhawk de la empresa 3D Robotics. Este autopiloto permite cargar y controlar una trayectoria de vuelo preprogramada, siguiendo además un perfil de altura durante la misión.

La carga útil consiste en una pequeña cámara digital de foto con 5 Megapixel de resolución y con un lente de gran angular. La cámara se controla de forma automática desde el sistema de autopiloto, quien asegura de esta manera el traslape predefinido entre cada foto. La orientación de la cámara se controla con un sistema gimbal de dos grados de libertad, quien mantiene la cámara siempre apuntando en la misma dirección, independiente del movimiento del multicóptero. Con todo esto, es posible realizar misiones de vuelo de forma completamente automática, manteniendo siempre un piloto de respaldo para casos de emergencia y para el recambio de baterías en caso de múltiples misiones.

Las imágenes digitales se graban en la memoria interna de la cámara y se descargan, junto con los datos de la trayectoria real, una vez finalizada la misión. Los datos de trayectoria se obtiene de la telemetría del autopiloto y contienen la información de posición, altura y orientación del UAV en el momento de la toma de imágenes. Estos datos facilitan posteriormente el análisis de las imágenes y la reconstitución de la geometría 3D del edificio, incluyendo su orientación y ubicación absoluta. La exactitud de la geometría obtenida depende de la resolución de la cámara y de la altura de vuelo sobre el techo del edificio. En condiciones óptimas de iluminación y traslape entre las fotos, se puede alcanzar una incertidumbre geométrica equivalente a 3 veces la resolución espacial de la foto (cm/pixel). La incertidumbre en la ubicación geográfica absoluta del modelo obtenido depende de la exactitud del GPS a bordo del autopiloto, que en general es de5 a 10 metros. Se puede mejorar esta incertidumbre en la ubicación utilizando un par de puntos de control en tierra con coordenadas conocidas. Luego las imágenes son procesadas en Photomodeler con calibración de la cámara y puntos de vista, generando una nube de puntos transferida a modelación 3D y luego al entorno BIM.

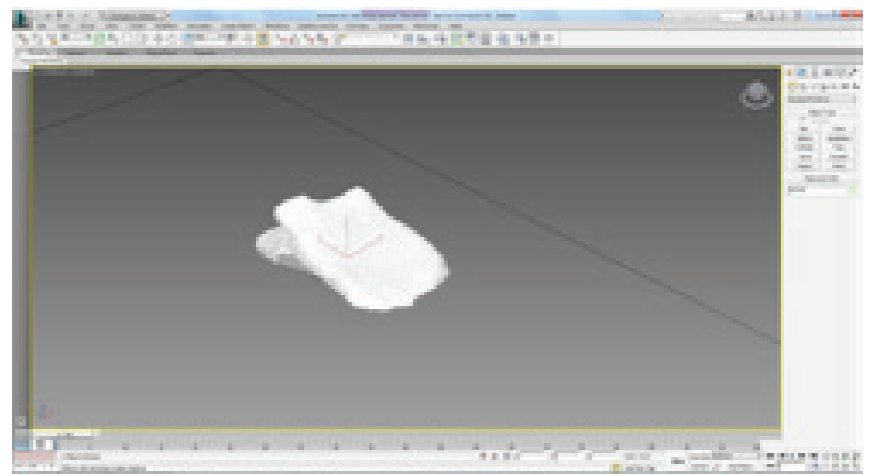




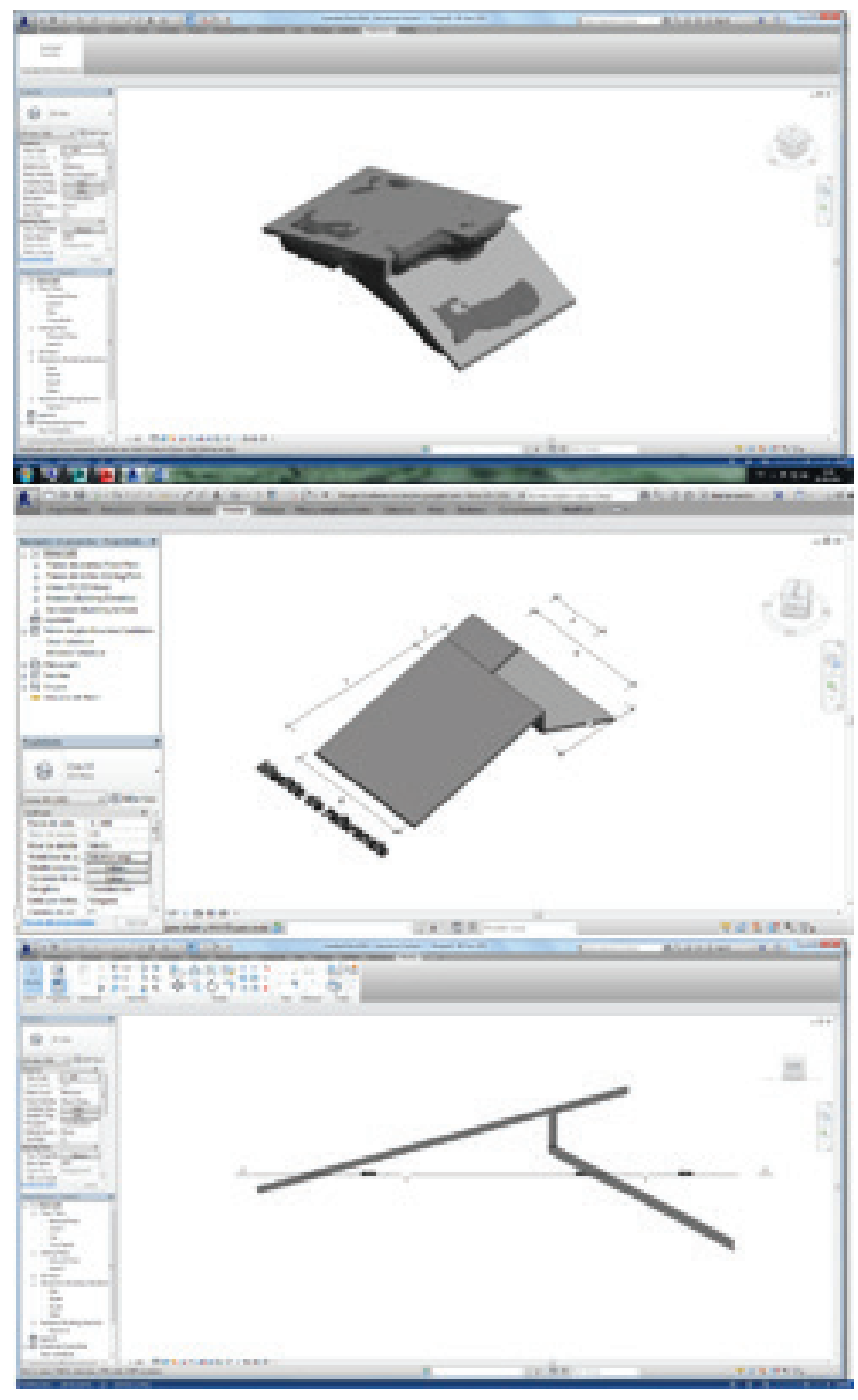

Figura 5: Restitución Geométrica de la Techumbre en entorno BIM.
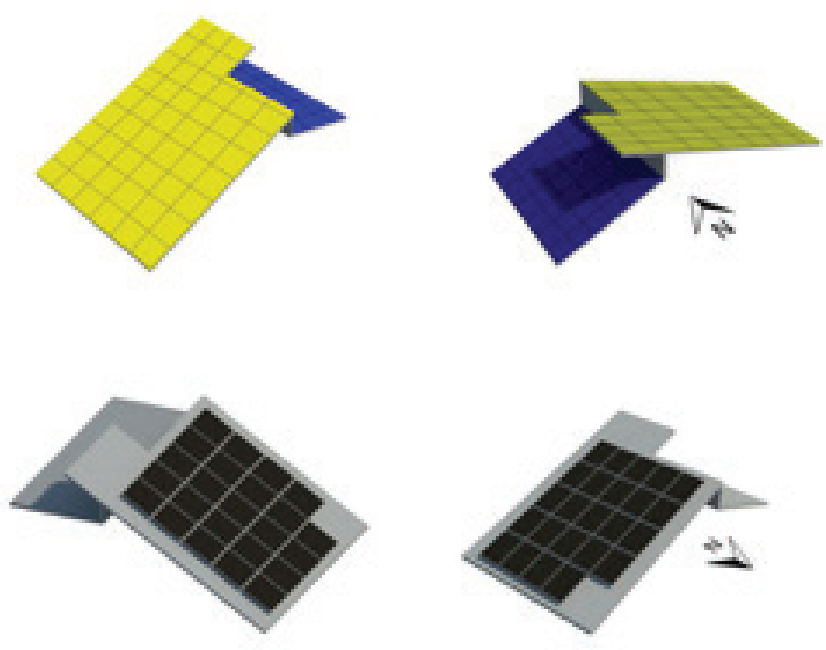

Figura 6: Análisis de Radiación Solar recibida e Integración de Paneles Solares Híbridos (BIPV-T).
Posteriormente se realiza el análisis de radiación solar recibida y la panelización de la cubierta para integrar diferentes tipos de captadores solares, en que se calcula su capacidad de aporte energético en relación a la demanda del edificio, en los distintos periodos estacionales.

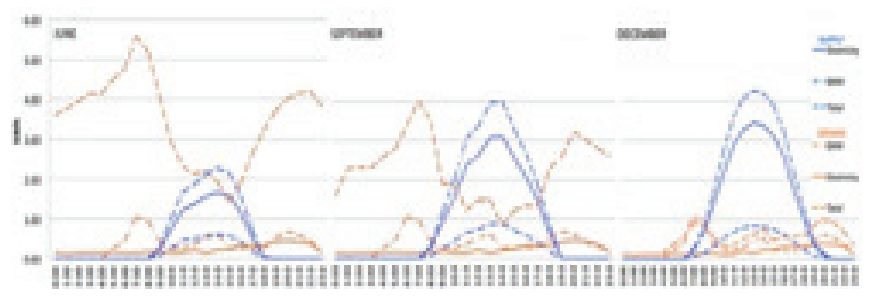

Figura 7: Análisis de Generación Energética (azul) en relación a la Demanda (rojo) en días típicos de Invierno, Primavera-Otoño y Verano (E.Zalamea).

\section{Resultados}

En la vivienda de ejemplo analizada se identificó el área de cubierta mejor orientada ( $75^{\circ}$ de azimuth) de $42 \mathrm{~m} 2$, en que se puede ocupar un 70\% para integrar 24 paneles solares híbridos (que combinan capacidades térmicas y fotovoltaicos), los cuales pueden llegar a generar el doble de la demanda eléctrica (lo restante se puede aportar a la red urbana), casi el total de agua caliente sanitaria y cerca de la mitad de calefacción (la diferencia se puedereponer con el aporte urbano). Esta provisión integrada en la techumbre puede otorgar una relevante (aunque no total) autonomía energética de la vivienda, proveyendo a su funcionamiento regular a partir de fuentes limpias (Tabla 1), y por ende reduciendo sustancialmente el impacto ambiental por ocupación (vida útil).

\begin{tabular}{|l|l|l|l|l|}
\hline \multicolumn{4}{|l|}{ Demanda (kWh) } & \multicolumn{4}{l|}{ Generación (kWh) } \\
\hline $\begin{array}{l}\text { Térmico } \\
\text { (DWH): }\end{array}$ & 9.19 & $\begin{array}{l}\text { Térmico } \\
\text { (DWH): }\end{array}$ & 6.09 & $66 \%$ \\
\hline $\begin{array}{l}\text { Térmico } \\
\text { (Calefacción) }\end{array}$ & 39.24 & $\begin{array}{l}\text { Térmico } \\
\text { (Calefacción) }\end{array}$ & 8.73 & $22.4 \%$ \\
\hline $\begin{array}{l}\text { Térmico } \\
\text { Total }\end{array}$ & 48.43 & $\begin{array}{l}\text { Térmico } \\
\text { Total }\end{array}$ & 14.83 & $30.7 \%$ \\
\hline Electricidad & 5.54 & Electricidad & 8.48 & $153.7 \%$ \\
\hline Total & 53.97 & Total & 23.30 & $44,70 \%$ \\
\hline
\end{tabular}

Tabla 1. Estimación de Demanda y Generación Energética en caso de Estudio.

Las pruebas realizadas a la fecha han permitido determinar la organización de un proceso efectivo, fiable y novedoso para estimar instalaciones solares en techumbres de edificios por evaluación aérea. Aunque implica la concertación de distintos programas y tareas, puede ser implementado con recursos de trabajo profesional usual en la zona. Las trayectorias definidas permitieron definir tres vistas 
fundamentales, aproximadamente a 1,5 anchos de distancia y 1 de altura, en separaciones de $130^{\circ}$, que permiten recoger visual y geometricamente mas del $95 \%$ de la cubierta, con una adecuada interpretación constructiva para integrar paneles solares. Implementado en una programación paramétrica a partir de un punto base de despegue que puede guiar el vuelo. Aportando luego a la simulación de radiación y cálculo de tecnologías posibles. Las experiencias desarrolladas han permitido estimar la factibilidad de instalación en edificios sobre el 50\% del área de cobertura y en viviendas del $80 \%$. Considerando la relación de área edificada, en viviendas de uno a dos pisos, la recolección estimada supera el consumo eléctrico anual (con aportes a la red de tres veces lo recolectado) y sobre la mitad de demanda en agua caliente y calefacción (debido a que es mayor en invierno, con menor radiación y los equipos térmicos son más costosos y no se pueden utilizar los excedentes). Mientras en edificios las instalaciones pueden proveer demandas eléctricas hasta de tres pisos habitables.

\section{Conclusiones}

El procedimiento debe ser cabalmente implementado para disponerlo como una herramienta profesional que apoye las instalaciones solares integrados. Verificando su desempeño en algunas ejecuciones completas. La programación de vuelos debe ser asegurada para el vehículo aéreo con suficiente flexibilidad para que el controlador enfrente variaciones climáticas u obstrucciones. Igualmente es probable que en algunas localizaciones se presenten salientes o configuraciones complejas que dificulten o extiendan el proceso definido, y deba ser complementado con otras tareas. La integración de datos entre las imágenes, el modelo geométrico en BIM, la simulación de radiación y el cálculo de paneles debe ser adecuadamente calibrada y automatizada, confirmándolo en una variedad de casos para asegurar su fiabilidad. En todo caso la estrategia planteada sugiere una capacidad eficaz para integrar sistemas renovables en la construcción existente, aliviando de manera relevante el amplio impacto ambiental de las ciudades. Proveyendo a profesionales locales de recursos de análisis adecuados para sugerir implementaciones solares integradas.

\section{Agradecimientos}

Conicyt AKA-ERNC 007. Además se agradece la colaboración del Ing. Aer. Esteban Chávez en el control de vuelos de prueba, y del Ing. Inf. Nicolas Lazcani en el procesamiento de imágenes y del Mg. Arqto. Esteban Zalamea en el procedimiento de integración de paneles solares.

\section{References}

Agugiaro, G., Nex, F., Remondino, F., Filippi, R. De, Droghetti, S., Furlanello, C., \& Foundation, B. K. (2012). Solar radiation estimation on building roofs and web-based solar cadastre, I(September), 177-182

Alexander, C., Smith-Voysey, S., Jarvis, C., \& Tansey, K. (2009). Integrating building footprints and LiDAR elevation data to classify roof structures and visualise buildings. Computers, Environment and Urban Systems, 33(4), 285-292

Bazjanac, V. (2008). IFC BIM-Based Methodology for SemiAutomated Building Energy Performance Simulation. Lawrence Berkeley National Laboratory: Building Technologies Department.

Eastman, C., Teicholz, P., Sacks, R., \& Liston, K. (2011). BIM Handbook. A guide to Building Information Modeling for Owners Managers, Designers, Engineers, and Contractors. New Jersey: John Wiley and Sons.

García Alvarado; Alvarez; Parra; Berrios (2004) Geometry of Movement: Displacements of the Viewpoint in Architectural Animations], SIGraDi 2004 - [Proceedings of the 8th Iberoamerican Congress of Digital Graphics] Porte Alegre Brasil 10-12 november 2004

Hachem, C. 2012. Investigation of Design Parameters for Increased Solar Potential of Dwellings and Neighborhoods. Ph.Thesis Concordia University

Jun M. y Andrea, R; "Path Planning For Unmanned Aerial Vehicles in Uncertain and Adversial Environments", Cooperative Control: Models, Applications and Algorithms, Cooperative Systems Volume 1, 2003, pp 95-110

Keller, T. E., Cusick, G. R., \& Courtney, M.E. (2007). Approaching the transition to adulthood: Distinctive profiles of adolescents aging out of the child welfare system. Social Services Review, 81, 453- 484.

Lobos, D., Wandersleben, G., and Castillo, L. (2014) Interoperability Map between BIM and BPS Software. Computing in Civil and Building Engineering (2014): pp. 601608.

Lund, P. Large-scale urban renewable electricity schemes Integration and interfacing Aspects. Energy Conversion and Management, 2012, n 63, pp. 162-172

Melsom, James ; Fraguada, Luis ; Girot, Christophe (2012) Synchronous Horizons: Redefining Spatial Design in Landscape Architecture Through Ambient Data Collection and Volumetric Manipulation, ACADIA 12: Synthetic Digital Ecologies,San Francisco 18-21 October, 2012), pp. 355-361 Williams, J. H. (2008). Employee engagement: Improving participation in safety. Professional Safety, 53(12), 40-45. 